\title{
面内曲げと圧縮を受ける鋼板の極限強度の評価法に関する研究 \\ EVALUATION OF ULTIMATE STRENGTH OF STEEL PLATES WITH INITIAL IMPERFECTIONS UNDER IN-PLANE BENDING AND COMPRESSION
}

\author{
奈良敬*・津田真**. 福本唀士*** \\ By Satoshi NARA, Makoto TSUDA and Yuhshi FUKUMOTO
}

\begin{abstract}
There are few studies on the ultimate strength of steel plates under in-plane combined loading, and their basic strength curves in the design specifications in many countries are still based on the elastic buckling theory using relevant safety factors. Evaluation in the ultimate strength is essential to promote the ultimate limit-state design method. This paper presents the ultimate strength of plate panel under in-plane stress gradient. Based on the analytical results, the ultimate strength formulas for uniform compress and pure bending are proposed, respectively and the interaction formula for the combined loading of compression and bending are then proposed.

Keywords: steel plate, in-plane combined loading, ultimate strength formula, interaction formula, initial imperfection
\end{abstract}

\section{1. まえがき}

1969 年から 1971 年にかけての一連の落橋事故が, 各 国示方書の座屈規定の見直し，あるいは規定作成に拍車 をかけたことは事実である．イギリスでは鋼橋の設計実 施基準は，1982 年に公表された BS 5400 Part $3^{1)}$ にお いて規定されている．新基準の制定にあたっては， Merrison 委員会の最終報告 IDWR $^{21}$ さらにその後実施 された多数の実験ならびに理論的研究の成果が採り入れ られている. 西ドイツでは1978 年に, DASt Richtlinie $012^{3)}$ が公表された。いず DIN 18800 第 3 部の草案と して公表される予定である.わが国においては, 1976 年の本州四国連絡橋上部構造設計基準案 ${ }^{4)}, 1980$ 年の道 路橋示方書 ${ }^{5)}, 1983$ 年の鋼鉄道橋設計基準 ${ }^{6)}$ で, 主な示 方書の改正が終了した. 鋼鉄道橋設計標準は長谷川ら ${ }^{7), 81}$ の研究成果に基づいている. 本州四国連絡橋上部構造設 計基準案においては, 宇佐美ら ${ }^{9}$ の研究成果が採り入れ られている.このように, 落橋事故後に新しく改正され

* 正会員 工博 岐阜大学助手 工学部土木工学科

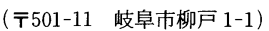

** 正会員 鹿島建設(株)土木設計本部 (T160 新宿区西新宿 2-1-1)

*** 正会員 工博 大阪大学教授 工学部土木工学科 ( ₹565 吹田市山田丘 2-1)
た示方書においては,

(1) 弾塑性有限変位挙動をどのように把握している か,

(2) 初期不整をどのように取り扱っているか,

(3) (1)，(2)を考虑して, 設計公式をどのように表現す るか,

などが注目すべき点といえる.

面内曲げと圧縮を受ける鋼板に関しては，

（ｉ） 1 軸曲げの場合，圧縮フランジが破壊に至るま で腹板を保たせるための腹板の設計法

（ii） 2 軸曲げを受ける場合の板要素の設計法（フラ ンジと腹板の区別ができない)

などの理由から，その基本強度を明らかにする研究が必 要である.

本研究においては, 面内曲げと圧縮を受ける鋼板につ いて, 数值計算により得られた極限強度をもとにして, 極限強度の相関曲線と純圧縮および純曲げを受ける場合 の極限強度曲線を用いて，面内曲げと圧縮を受ける鋼板 の極限強度の評価法について考察を行う.さらに, 道路 橋示方書を例にとり, 本評価法と示方書の耐荷力評価と の差異を明らかにした。本研究成果は, 限界状態設計法 において，極限強度に基づく鋼構造板要素の基本強度を 評価する観点から貢献できるものと考える. 


\section{2. 面内曲げと圧縮を受ける鋼板の極限強度の 算定}

数値計算にあたっては，文献 10）および 11）に示す 弾塑性有限変位解析法を用いた。

初期たわみは道路橋示方書（以下，「道示」とよぶ） の許容値とした. 残留応力については, 文献 12）に基 づいた．境界条件は周辺単純支持とする. 載荷方法につ いては，文献 13）に基づいた。 図一1 に載荷方法, 表一 1 に断面に関するパラメーターを示す.これらの数值計 算結果については文献 14）を参照されたい。なお表中, $t$ は板厚, $\sigma_{Y}$ は降伏応力度, $E$ はヤング係数, $\mu$ はポ アソン比である.

\section{3. 面内曲げと圧縮を受ける鋼板の極限強度の} 評価法

\section{（1）純圧縮応力および純曲げ応力が作用する鋼板の 極限強度曲線}

純圧縮および純曲げの場合の極限強度を表一2に示 す. 極限強度については $\varphi=0$ (純圧縮）のとき $N_{u} / N_{Y}$, $\varphi=2$ (純曲げ) のとき, $M_{u} / M_{Y}$ で表わす.ただし，

$N_{u}:$ 極限圧縮荷重

$N_{Y}: \sigma_{Y} b t$

$M_{u}:$ 極限面内曲げモーメント

$M_{Y}: \sigma_{Y} b^{2} t / 6$

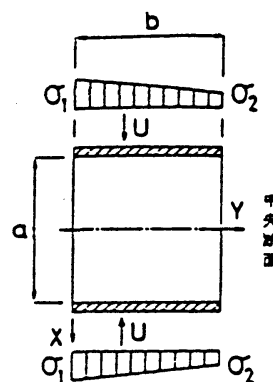

(a) $0 \leqq \varphi<2$

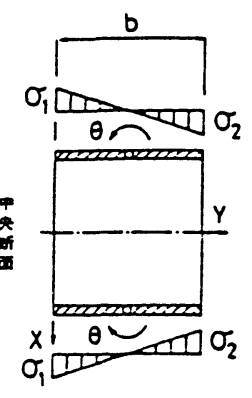

(b) $\varphi=2$
図一1 載荷方法

表一1 パラメーター

\begin{tabular}{|c|c|}
\hline \multicolumn{2}{|c|}{ - 蝠园比バラメータ： } \\
\hline$R=\frac{b}{t}$ & $\sqrt{\frac{\sigma_{Y}}{E} \frac{12\left(1-\mu^{2}\right)}{\pi^{2} k}}$ \\
\hline 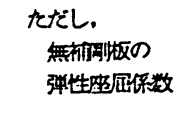 & $k=\left\{\begin{array}{r}8.4 /(\psi+1.1), \\
0 \leq \psi \leq 1 \\
10 \psi^{2}-6.27 \psi+7.63, \\
-1 \leq \psi<0\end{array}\right.$ \\
\hline 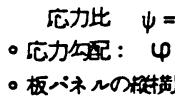 & $\begin{array}{l}1-\varphi \\
=\left(\sigma_{1}-\sigma_{2}\right) / \sigma_{1} \\
\text { 比: } a / b\end{array}$ \\
\hline
\end{tabular}

表一2 の値を図一2にプロットし，最小二乗法を用いて 次式（1）に示す近似式を利用すると精度よく表わされ ることがわかった。

$$
\frac{N_{u}}{N_{Y}} \text { or } \frac{M_{u}}{M_{Y}}=\left(\frac{R_{c r}}{R}\right)^{\beta}
$$

この近似式で極限強度を表わすと式（2）（５）のよう になった。

a) $\sigma_{r c} / \sigma_{Y}=-0.4, \varphi=0$ の場合

$\frac{N_{u}}{N_{Y}}=\left(\frac{0.453}{R}\right)^{0.495} \leqq 1.0$

b) $\sigma_{r c} / \sigma_{Y}=0, \varphi=0$ の場合

$\frac{N_{u}}{N_{Y}}=\left(\frac{0.451}{R}-\right)^{0.511} \leqq 1.0$

c) $\sigma_{r c} / \sigma_{Y}=-0.4, \varphi=2$ の場合

$\frac{M_{u}}{M_{Y}}=\left(\frac{1.21}{R}\right)^{0.420} \leqq 1.5$

d) $\sigma_{r c} / \sigma_{Y}=0, \varphi=2$ の場合

$\frac{M_{u}}{M_{Y}}=\left(\frac{0.790}{R}\right)^{0.594} \leqq 1.5$

ここで， $R_{c r}$ は式 $(2) \sim(5)$ において右辺が 1 となる

表一2 純圧縮および純曲げ時の極限強度

\begin{tabular}{|c|c|c|c|c|c|c|}
\hline & \multicolumn{5}{|c|}{$\mathbf{R}$} \\
\hline & & 0.5 & 0.7 & 0.9 & 1.1 & 1.3 \\
\hline \multirow{2}{*}{$\varphi=2$} & $\sigma_{Y . . / \sigma_{Y}=-0.4}$ & 1.448 & 1.263 & 1.141 & 1.039 & 0.9705 \\
\hline & $\sigma_{\mathrm{C} C \mathrm{C}} / \sigma_{\mathrm{r}}=0$ & 1.294 & 1.090 & 0.9349 & 0.8225 & 0.7339 \\
\hline \multirow{2}{*}{$\varphi=0$} & $0.0 / \sigma_{r}=-0.4$ & 0.9393 & 0.8210 & 0.7179 & 0.6395 & 0.5725 \\
\hline & 0 red $/ \sigma_{y}=0$ & 0.9090 & 0.8057 & 0.7092 & 0.6292 & 0.5644 \\
\hline
\end{tabular}

表一3 極限強度曲線の誤差（\%)

\begin{tabular}{|c|c|c|c|c|c|c|}
\hline & \multicolumn{5}{|c|}{$\mathbf{R}$} \\
\hline & & 0.5 & 0.7 & 0.9 & 1.1 & 1.3 \\
\hline \multirow{2}{*}{$\varphi=2$} & $\sigma_{r e} / \sigma_{r}=-0.4$ & 0.3 & -0.2 & -0.6 & 0.3 & 0.1 \\
\hline & $\sigma r c / \sigma_{r}=0$ & 1.4 & -1.5 & -1.0 & -0.2 & 1.3 \\
\hline \multirow{2}{*}{$\varphi=0$} & $\sigma_{r e} / \sigma_{r}=-0.4$ & 1.4 & -1.8 & -0.8 & 0.8 & 3.6 \\
\hline & $\sigma_{r o / \sigma_{Y}}=0$ & 4.4 & -0.8 & -0.9 & 0.8 & 3.2 \\
\hline
\end{tabular}

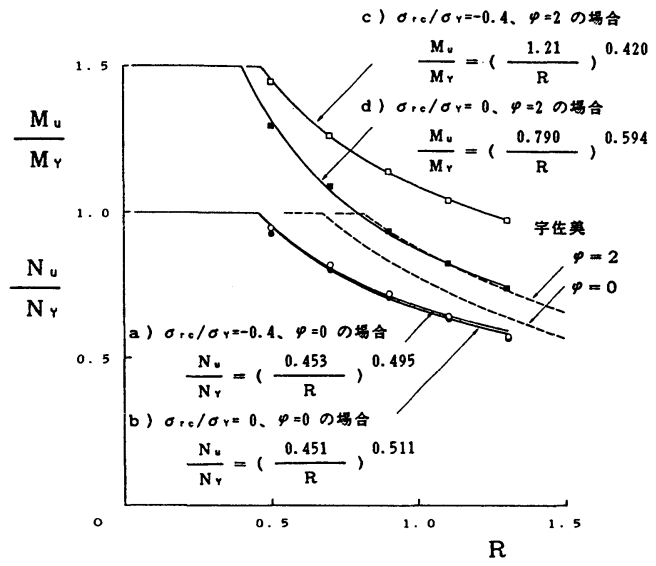

図一2＼cjkstart純圧縮または純曲げ時の極限強度曲線 
限界幅厚比パラメーター， $\sigma_{r c}$ は残留圧縮応力度である.

式 ( 2 ) 〜 ( 5 ) の極限強度曲線を図一2に実線で表わ す. $\varphi=0$ の場合, 縦横比 $a / b=0.5$ なので残留応力の 有無にかかわらずほとんど同じ曲線になる. 一方， $\varphi=$ 2 の場合, 残留応力のある方が, 残留応力のない方より 極限強度が大きく， $R$ が増すにつれその差は大きくな る.これは, 圧縮縁の残留引張応力度が極限強度に有利 に作用するためであり，文献 14）に示される極限状態 の応力分布から理解できる. また, 図中には宇佐美 ${ }^{15)}$ の 弾性有限変位解析結果に基づく耐荷力曲線を破線で併せ て示した. 宇佐美は箱形断面の腹板を対象として圧縮縁 の垂直応力度 $\sigma_{1}$ が $\sigma_{Y}$ に達した時点で腹板が終局限界に 達するという仮定を用いて耐荷力を評価しているため, 本研究によって得られた極限強度とは必ずしも一致しな い. しかし， $\varphi=2$ の場合は応力勾配により圧縮縁の応 力が最も大きいため, 上述の破壊の仮定を使用しても, $M_{u} / M_{Y} \leqq 1$ の範囲において残留応力のない場合の極限強 度曲線とよく一致することがわかる.

式（2)（ 5 ） の極限強度曲線を使って求めた極限強 度 $N_{u} / N_{Y}$ および $M_{u} / M_{Y}$ が解析結果をどれだけ精度よく 表わすかを示したのが表一 3 である. $\varphi=2$ の場合, 精 度はよいが, $\varphi=0$ のほうは $R=0.5,1.3$ の場合の精度 が若干低下する。しかし, 全体としてはほぼ精度のよい 極限強度曲線が得られるので, この極限強度曲線を用い て純圧縮および純曲げの場合の極限強度を評価すること ができる.なお, 道示では $M_{u} / M_{Y} \leqq 1$, プレートガーダー の腹板では $M_{u}$ はせいぜい $1.15 M_{Y}$ 以下程度であるが, ここでは板要素として取り扱っているので $M_{u} / M_{Y} \leqq 1.5$ となる。

\section{（2）面内曲げと圧縮を受ける鋼板の極限強度の相関} 曲線

図-3 と図一 4 に残留応力がある場合および残留応力 がない場合の極限強度の相関曲線を示す. 縦軸 $N_{u}^{*}$ は極 限圧縮荷重 $N_{u}$ を純圧縮応力作用時の極限圧縮荷重 $\left(N_{u}\right)_{\varphi=0}$ で無次元化した值, 横軸 $M_{u}^{*}$ は極限面内曲げモ一 メント $M_{u}$ を純曲げ応力作用時の極限面内曲げモーメン $卜\left(M_{u}\right)_{\varphi=2}$ で無次元化した値である.すなわち， $N_{u}^{*}=N_{u} /\left(N_{u}\right)_{\varphi=0}$

$M_{u}^{*}=M_{u} /\left(M_{u}\right)_{\varphi=2}$

図中のプロットした記号が解析結果を示し, 実線が式 （８）で表わす極限強度の相関曲線である. 幅厚比パラ メーター $R$ を $0.5,0.9,1.3$ と変化させている.これら の図より，次の事柄がわかった。

(1) 極限強度の相関曲線は, $N_{u}^{*}>M_{u}^{*}$ の領域で破線 から遠ざかり， $N_{u}^{*}<M_{u}^{*}$ の領域では破線に近づい ており，この傾向は $R$ が大きくなるほど顕著であ る.

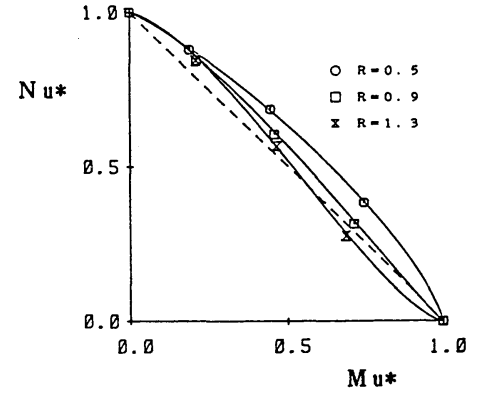

図一3 極限強度の相関曲線（残留応力あり）

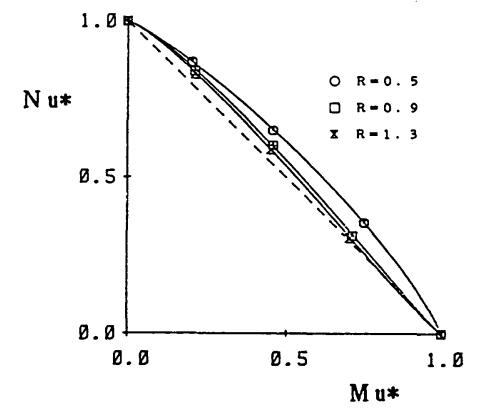

図一4 極限強度の相関曲線（残留応力なし）

表一4 幅厚比パラメーターと指数の関係

\begin{tabular}{|c|c|c|c|c|c|}
\hline \multicolumn{2}{|c|}{} & \multicolumn{2}{|c|}{$\sigma_{r c / \sigma} / \sigma_{r}=-0.4$} & \multicolumn{2}{c|}{$\sigma_{r c} / \sigma_{r}=0$} \\
\cline { 3 - 7 } & $p$ & $q$ & $p$ & $q$ \\
\hline \multirow{4}{*}{$R$} & 0.5 & 1.025 & 1.244 & 1.206 & 1.171 \\
\cline { 2 - 6 } & 0.7 & 1.100 & 1.233 & 1.017 & 1.219 \\
\cline { 2 - 6 } & 0.9 & 0.900 & 1.322 & 0.926 & 1.251 \\
\cline { 2 - 6 } & 1.1 & 0.787 & 1.376 & 0.908 & 1.234 \\
\cline { 2 - 6 } & 1.3 & 0.670 & 1.490 & 0.893 & 1.227 \\
\hline
\end{tabular}

表一5 本評価法における極限強度の誤差（\%) $\left(\sigma_{r c} / \sigma_{Y}=-0.4\right)$

\begin{tabular}{|c|c|c|c|c|c|c|c|}
\hline & \multicolumn{5}{|c|}{$\mathrm{R}$} \\
\hline & & & 0.5 & 0.7 & 0.9 & 1.1 & 1.3 \\
\hline \multirow{6}{*}{$\varphi$} & \multirow{2}{*}{0.5} & $\mathrm{Nu}_{u} / \mathrm{N}_{r}$ & 1.1 & 0.4 & 0.6 & 0.4 & 0.6 \\
\hline & & $\mathrm{Mu}_{\mathrm{u}} / \mathrm{Mr}_{\mathrm{r}}$ & 0.8 & 0.4 & 0.6 & 0.7 & 0.6 \\
\hline & \multirow{2}{*}{1.0} & $\mathrm{Nu} / \mathrm{N}_{\mathrm{r}}$ & -0.8 & -0.6 & -0.0 & -1.1 & -0.2 \\
\hline & & $\mathrm{Hu}_{\mathrm{u}} / \mathrm{Mr}_{\mathrm{r}}$ & -0.8 & -0.6 & -0.0 & -1.1 & -0.2 \\
\hline & \multirow{2}{*}{1.5} & $\mathrm{Nu} / \mathrm{N}_{\mathrm{r}}$ & 0.5 & -0.4 & 1.2 & -0.5 & 0.3 \\
\hline & & $\mu_{u} / M_{r}$ & 0.5 & -0.3 & 1.2 & -0.5 & 0.3 \\
\hline
\end{tabular}

表一 6 本評価法における極限強度の誤差（\%) $\left(\sigma_{r c} / \sigma_{Y}=0\right)$

\begin{tabular}{|c|c|c|c|c|c|c|c|}
\hline & \multicolumn{5}{|c|}{$\mathrm{R}$} \\
\hline & & & 0.5 & 0.7 & 0.9 & 1.1 & 1.3 \\
\hline \multirow{6}{*}{$\varphi$} & \multirow{2}{*}{0.5} & $\mathrm{Nu} / \mathrm{Nr}_{\mathrm{r}}$ & -0.1 & 0.5 & 0.3 & 0.5 & 0.3 \\
\hline & & $\mathrm{Mu} / \mathrm{Mr}_{\mathrm{r}}$ & -0.1 & 0.4 & 0.3 & 0.5 & 0.3 \\
\hline & \multirow{2}{*}{1.0} & $\mathrm{Nu} / \mathrm{N}_{\mathrm{r}}$ & 0.1 & -0.3 & -0.6 & -0.3 & -0.3 \\
\hline & & $\mathrm{Mu} / \mathrm{Mr}_{\mathrm{r}}$ & 0.1 & -0.3 & -0.6 & -0.3 & -0.3 \\
\hline & \multirow{2}{*}{1.5} & $\mathrm{Nu} / \mathrm{N}_{\mathrm{r}}$ & 0.0 & 0.2 & 0.3 & 0.3 & 0.2 \\
\hline & & $\mathrm{Mu} / \mathrm{Mr}$ & 0.0 & 0.0 & 0.3 & 0.2 & 0.2 \\
\hline
\end{tabular}


(2) 図中に記した点は 1 点を除いて, 図中の破線で示 された直線 $N_{u}^{*}+M_{u}^{*}=1$ の外側にあることから, 図 中の破線が下限值を捉えている.

(3) 相関曲線では残留応力の有無による差異は, $R$ の大きい場合には少し認められるが，小さいもので ある.

ここで, 式 (8) に示す極限強度の相関曲線の指数 $p, q$ に影響を与えるパラメーターとして $R$ だけを考 え，おのおのの $p, q$ より最小二乗法を用いて $p, q$ を $R$ の 2 次式で表わすと精度がよく,式( 9 )および式(10) のようになった. 指数 $p, q$ と幅厚比パラメーター $R$ と の関係は表一4のとおりである.

$$
\begin{aligned}
& \left(N_{u}^{*}\right)^{p}+\left(M_{u}^{*}\right)^{q}=1 \\
& p=0.468 R^{2}-1.63 R+2.00 \\
& q=0.041 R^{2}+0.340 R+0.974 \cdots \\
& \left(\sigma_{r c} / \sigma_{Y}=-0.4\right) \\
& p=0.782 R^{2}-1.77 R+1.88 \\
& q=-0.250 R^{2}+0.523 R+0.968 \text {. } \\
& \left(\sigma_{r c} / \sigma_{Y}=0\right)
\end{aligned}
$$

式（８）の相関式を使って求めた $N_{u}$ と $M_{u}$ がどれだけ の精度を有するかを表わしたのが表一5および表一6で ある. 残留応力がある場合, 最大でも $\pm 1.2 \%$ の誤差し かないのがわかる. 残留応力がない場合, もっと精度が よく $0.6 \%$ 以内の誤差であった. また， $R$ および $\varphi$ で整理して誤差の影響を調べた結果， $R$ と $\varphi$ に無関係 であるのがわかった．面内曲げと圧縮を受ける板につい て, 幅厚比パラメーターRだけをパラメーターとして, 式 (8) で示される極限強度の相関曲線を用いると, $R$ と $\varphi$ に無関係に精度よく耐荷力を評価できることがわ かる.

\section{4. 応力勾配による係数に関する考察}

面内曲げと圧縮を受ける鋼板について，道示において は圧縮板の基準耐荷力曲線をもとにして, 応力勾配によ る係数 $f$ を用いて設計する. 本節ではこの $f$ を用いて, 道示の耐荷力曲線と本研究で得られた極限強度曲線の差 異について明らかにする.

面内曲げと圧縮を受ける場合，応力勾配 $\varphi=0,1,2$ の值に対し, 座屈係数 $k=4.0,7.8,23.9$ となる. 面内 曲げが主な場合は板が座屈しても直ちに耐荷力は失わ ず，なお荷重に耐えることができる，そこで，純圧縮に 対する限界幅厚比パラメーター $R_{c r, c}$, 曲げに対するも のを $R_{c r, B}$ とし, その間の限界幅厚比パラメーターを $\varphi$ の 1 次式で表わすと,

$$
R_{c r}=R_{c r, c}+\left(R_{c r, B}-R_{c r, c}\right) \varphi / 2 \text {. }
$$

となる. また, 安全率 $\nu$ も $\varphi$ によって変化し, 次式の ようになる。

\section{表一7 応力勾配による係数（道路橋示方書）}

\begin{tabular}{|c|c|c|c|}
\hline$\varphi$ & 0 & 1 & 2 \\
\hline$f$ & 1 & 1.78 & 3.86 \\
\hline
\end{tabular}

$\nu=1.7-0.15 \varphi$

道示の基準耐荷力曲線は式 (13), 許容応力度曲線は式

（14）で表わされるから,

$$
\begin{aligned}
& \frac{\sigma_{c r}}{\sigma_{Y}}=\left(\frac{R_{c r}}{R}\right)^{2} \cdots \\
& \frac{\sigma_{a}}{\sigma_{Y}}=\frac{1}{\nu}\left(\frac{R_{c r}}{R}\right)^{2} .
\end{aligned}
$$

$\varphi$ が異なる板で $R$ が等しい場合は，

$$
\frac{1}{\sqrt{\nu}} \frac{R_{c r}}{R}=\text { const. } \cdots
$$

となる。ゆえに，

$$
\begin{aligned}
& \frac{1}{\sqrt{\nu_{c}}} \frac{R_{c r, c}}{(b / t)_{c} \sqrt{\sigma_{Y} / E \cdot 12\left(1-\mu^{2}\right) / \pi^{2} k_{c}}} \\
& =\frac{1}{\sqrt{\nu}} \frac{R_{c r}}{b / t \sqrt{\sigma_{Y} / E \cdot 12\left(1-\mu^{2}\right) / \pi^{2} k}} \\
& \frac{1}{\sqrt{\nu_{c}}} \frac{R_{c r, c} \sqrt{k_{c}}}{(b / t)_{c}}=\frac{1}{\sqrt{\nu}} \frac{R_{c r} \sqrt{k}}{b / t}
\end{aligned}
$$

である.

応力勾配による係数 $f$ は

$$
f=\frac{b / t}{(b / t)_{c}}
$$

であるから，式（16）より次式のようになる.

$$
f=\frac{R_{c r}}{R_{c r, c}} \sqrt{\frac{k \cdot \nu_{c}}{k_{c} \cdot \nu}}
$$

道示では, $R_{c r, c}=0.7, R_{c r, B}=1.0, \varphi=0,1,2$ に対し て $k=4,7.8,23.9$ および $\nu=1.7,1.55,1.4$ として, 式 (18) に代入して $f$ を求め (表一7参照), これを $\varphi$ の 2 次の関数として最小二乗法により次式のような近似 式を求めている.

$$
f=0.65 \varphi^{2}+0.13 \varphi+1
$$

ここでは, 式 $(2) \sim(5)$ で求めた純圧縮 $(\varphi=0)$, 純曲げ $(\varphi=2)$ 時の極限強度曲線のほかに, $\varphi=0.5$, $1.0,1.5$ の場合における極限強度の指標 $K_{u}{ }^{14)}$ を用い て，式（17）で定義される係数 $f$ を計算した。ただし， $K_{u}$ は次式で定義される.

$$
K_{u}=\frac{N_{u}}{N_{Y}}+\frac{M_{u}}{M_{Y}}
$$

したがって， $\varphi=0$ のときは $K_{u}=N_{u} / N_{Y}, \varphi=2$ のとき は $K_{u}=M_{u} / M_{Y}$ となる. 極限強度に基づく係数 $f$ は次 のようにして求めた。すすなわち， $\varphi=0$ のとき式（2） において $R=R_{c}, R_{c r}=R_{c r, c}$ とすれば

$$
\frac{N_{u}}{N_{Y}}=\left(\frac{R_{c r, c}}{R_{c}}\right)^{0.495}
$$




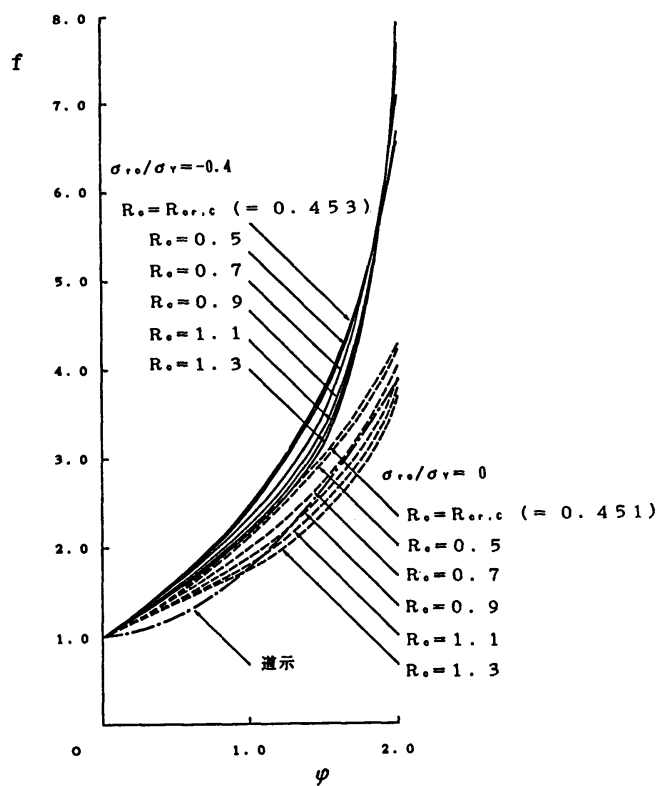

図一5 応力勾配による係数

一方， $0<\varphi \leqq 2$ のきは

$$
K_{u}=\left(\frac{R_{c r}}{R}\right)^{\beta}
$$

ここで, 式 (21) と式 (22) を等置して $R$ について解 けば，次式が得られる.

$$
R=R_{c r}\left(\frac{R_{c}}{R_{c r, c}}\right)^{0.495 / \beta}
$$

これより, 表一1 中の座屈係数 $k$ を用いて $f$ は次式で 計算できる.

$$
f=\frac{R}{R_{c}}\left(\frac{k}{4}\right)^{0.5}
$$

残留応力がない場合についても式（3）を使って同様に 計算できる，その結果を図一 5 に示す，図中，実線は残 留応力がある場合，破線は残留応力がない場合を示す.

式 (24) からわかるように, 極限強度より得られる $f$ は $R_{c}$ の值によって変化するので $R_{c r, c} \leqq R_{c} \leqq 1.3$ の範囲 で求めている. 図中の一点鎖線は式 (19) に示す道示の $f$ 值を表わす. 極限強度に基づいて求めた $f$ 値は次の ような傾向を示す.

(1) $f$ 值は $R_{c}$ によって変化する.

(2) 残留応力がある場合の方が，ない場合より $f$ 值 が大きく，その差は $\varphi$ が大きくなるに従い拡大す る.

(3) 道示の $f$ 値は $\sigma_{1}=\sigma_{Y}\left(K_{u}=1\right)$ のときに求めたも のであるから， $R_{c}=R_{c r, c}$ の場合の $f$ 值と比較する 亡，常に極限強度に基づく $f$ 值の方が大きい.

以上より, 実際的な残留応力をもつ鋼板では $\varphi$ の大き
い領域で道示の場合より幅厚比を大きくすることができ

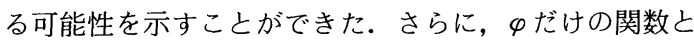
ならない $f$ 値を用いるより極限強度の相関曲線を用い る方が実際的であると思われる.

\section{5. 結 論}

本研究において得られた結論を列挙すれば次のとおり である。

（1）純圧縮応力および純曲げ応力が作用する鋼板の 極限強度曲線を幅厚比パラメーター $R$ と限界幅厚比パ ラメーター $R_{c r}$ をパラメーターとした近似式で表わし た. そして，この極限強度曲線を用いて極限強度を精度 よく評価できることがわかった.

（2） $N_{u}^{*}, M_{u}^{*}$ を用いて極限強度の相関曲線を作成し た結果，次のことがわかった。

(1) 極限強度の相関曲線は, 残留応力の有無によって ほとんど変化しないが, 幅厚比パラメーター $R$ に よって変化する.

(2) 極限強度の相関曲線は, $N_{u}^{*}>M_{u}^{*}$ の領域で直線 $N_{u}^{*}+M_{u}^{*}=1$ から遠ざかり, $N_{u}^{*}<M_{u}^{*}$ の領域では直 線 $N_{u}^{*}+M_{u}^{*}=1$ に近づく.

(3) 極限強度の相関曲線を直線 $N_{u}^{*}+M_{u}^{*}=1$ で表わす と下限值を捉えることができる.

さらに，極限強度の相関曲線の指数 $p, q$ を, 幅厚比 パラメーター $R$ をパラメーターとした近似式で表わす ことにより十分精度の高い極限強度の評価ができること がわかった。

（3） 応力勾配による係数 $f$ を極限強度に基づいて 求めた結果, 次のことがわかった.

(1) 残留応力のある実際的な鋼板では $\varphi$ の大きい領 域で道示の場合より幅厚比を大きくすることが可能 である。

(2) $f$ は $\varphi$ のかに $R_{c}$ によっても変化するので，極 限強度の相関曲線を用いた方が実際的である.

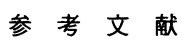

1) BS 5400, "Code of Practice for Design of Steel Bridges”, Steel, Concrete and Composite Bridges, Part 3, British Standards Institution, 1982.

2) Committee of Inquiry into the Basis of Design and Method of Errection of Steel Box Girder Bridge, "Interim Design and Workmanship Rules", Her Majesty's Stationary Office, 1973.

3) Deutscher Ausschuss für Stahlbau-Richtlinien : DASt Ri-012, 1978.

4）本州四国連絡橋公団：本州四国連絡橋上部構造設計基 準·同解説 (案), 昭和 51 年 3 月.

5）日本道路協会：道路橋示方書・同解説，昭和 55 年 2 月.

6) 土木学会：鋼鉄道橋設計標準 - 同解説，昭和 58 年 4 月. 
7）長谷川彰夫・大田孝二・西野文雄：補剛された板要素の 坐屈強度に関する二, 三の考察, 土木学会論文報告集, 第 232 号, pp. 1 15, 1974 年 12 月.

8) Hasegawa, A. and Nishino, F. : A Limit State Design of Multiple Stiffened Plates under Combined Bending and Compression, Bulletin of Nagoya Institute of Technology, Vol.32, pp. 297 301, 1980.

9）宇佐美勉・福本唀士：圧縮力と曲げモーメントを受ける 補剛材つき板の座屈強度と設計, 土木学会論文報告集, 第 247 号, pp. 35 49, 1976 年 3 月.

10）小松定夫 ·奈良 敬・山口博章 : 初期不整を有し面内荷 重を受ける板の混合法による弾塑性有限変位解析, 昭和 58 年度関西支部年次学術講演会講演概要, I-32, 1983 年 5 月.

11）奈良 敬・出口恭司・小松定夫：ひずみ硬化を考慮した
圧縮板の極限強度に関する研究, 構造工学論文集, Vol. 33A, pp. 141 150, 1987 年 3 月.

12）小松定夫・牛尾正之・北田俊行 : 補剛板の溶接残留応力 および初期たわみに関する実験的研究, 土木学会論文報 告集, 第 265 号, pp. 25 35, 1977 年 9 月.

13）奈良 敬・山田浩幸・松永康男・小松定夫：面内曲げと 圧縮を受ける補剛板の極限強度に関する研究, 構造工学 論文集, Vol. 33 A, pp. 151 160，1987 年 3 月.

14）奈良 敬・小島治雄・津田 真・小松定夫：面内曲げと 圧縮を受ける鋼板の極限強度特性に関する研究，土木学 会論文集, 第 386 号 /I-8, pp. 275〜283，1987 年 10 月.

15) Usami, T. : Post-Buckling of Plates in Compression and Bending, Journal of Structural Division, Proc. of ASCE, Vol. 108, No. ST3, pp. 591 609, March, 1982.

(1987.5.22 - 受付) 